Relations industrielles

Industrial Relations

\title{
Cas pratiques
}

\section{Donat Quimper}

Volume 2, numéro 6, février 1947

URI : https://id.erudit.org/iderudit/1023862ar

DOI : https://doi.org/10.7202/1023862ar

Aller au sommaire du numéro

\section{Éditeur(s)}

Département des relations industrielles de l'Université Laval

ISSN

0034-379X (imprimé)

1703-8138 (numérique)

Découvrir la revue

Citer cet article

Quimper, D. (1947). Cas pratiques. Relations industrielles / Industrial Relations, 2(6), 4-4. https://doi.org/10.7202/1023862ar

Tous droits réservés (C Département des relations industrielles de l’Université Laval, 1947
Ce document est protégé par la loi sur le droit d'auteur. L'utilisation des services d'Érudit (y compris la reproduction) est assujettie à sa politique d'utilisation que vous pouvez consulter en ligne.

https://apropos.erudit.org/fr/usagers/politique-dutilisation/ 


\section{CAS PRATIQUES}

Est-il légal pour un employeur d'infliger à ses employés une perte de temps d'un quart d'heure par cinq minutes de retard au travail?

Par la même occasion, pourriez-vous m'indiquer à quel critérium l'on peut reconnaître la légalité d'une disposition contractuelle?

La légalité d'une disposition se juge à un critérium contenu dans les deux articles suivants du Code civil:

A-Art. 13: "On ne peut déroger par des conventions particulières aux lois qui intéressent l'ordre public ou les bonnes moeurs."

B-Art. 14: "Les lois prohibitives emportent nullité, quoiqu'elle n'y soit pas prononcée."

L'ordre public c'est celui dont le maintien intéresse l'existence même de la société. C'est à cette fin que sont ordonnés le droit constitutionnel, le droit administratif, le droit criminel, les lois concernant les droits de familles, celles touchant à l'état ou à la capacité des personnes, celles qui ont pour objet d'éviter la fraude ou de protéger les tiers et, en général, tout le droit public.

L'expression bonnes moeurs s'entend des moeurs conformes à la morale chrétienne.

Quant aux lois prohibitives ce sont celles qui comportent une défense de faire quelque chose. Et, l'article 14 du Code civil statue sur les conséquences de leur violation en décrétant que tout ce qui est fait en contravention de leurs dispositions est nul, alors même que la nullité ne serait pas prononcée.

Il ressort donc de ces quelques principes que le critérium en question comporte trois éléments essentiels dont il faut tenir un égal compte dans l'appréciation d'une disposition particulière. Telle disposition est-elle contraire à l'ordre public? Est-elle contraire aux bonnes moeurs? Est-elle contraire à quelque loi prohibitive? Si vous pouvez répondre non, dans chaque cas, la disposition dont il s'agit est évidemment légale. Par contre, si vous devez répondre oui ne fusse qu'à une seule de ces questions, la disposition concernée doit être jugée illégale.

Dans l'espèce, il s'agit de savoir si l'employeur a le droit d'exercer une sanction en perte de temps contre les employés en retard au travail.

En autant que son application n'entraîne pas une contravention aux salaires fixés par des décrets ou les ordonnances de la Commission du salaire minimum, cette pénalité ne nous paraît en rien contraire à l'ordre public. Elle n'est qu'une mesure disciplinaire tendant seulement à obtenir une rigoureuse ponctualité à l'emploi. Qui ne voit, du reste, dans les grandes industries où la rationali- sation a institué le travail à la châne, le préjudice qu'un employeur pcurrait subir du simple retard d'un employé à son poste? Des centaines d'opérations pourraient s'en trouver affectées...

Ce moyen de sanction serait-il davantage contraire aux bonnes moeurs? Non plus, sauf s'il était pratiqué sur une base d'exagération telle qu'il cesserait d'être une simple mesure disciplinaire pour devenir une affaire d'exploitation équivalant à vol.

Nous suggèrerions toutefois à l'employeur, pour éviter les dangers d'injustices dans certains cas particuliers, de ne pas "infliger" ces sanctions d'une façon trop impitoyable ni sur une base trop générale. Les cas de retards suffisamment motivés devraient être traités avec générosité.

Enfin, il n'existe pas de loi, que nous sachions, pour interdire à un employeur de pénaliser les employés en retard à leur travail. De sorte que, nous pouvons conclure, ayant répondu négativement à nos trois questions, que la façon d'agir de cet employeur vis-à-vis des employés retardataires n'a rien d'illégal, en autant qu'il exerce ces pénalités dans des limites raisonnables et qu'il ne s'en autorise pas pour enfreindre les dispositions d'un décret ou le minimum du salaire fixé par les ordonnances. Mais, en saines relations industrielles peut-on dire qu'une telle mesure disciplinaire est toujours sage? Nous préférerions que les sommes perçues comme amendes fussent versées dans un fonds spécial destiné à l'organisation de services sociaux dans l'entreprise.

Donat QUIMPER

\section{NOS COLLABORATEURS}

Omer Genest, ptre, Conseiller moral du Conseil Régional Saguenay-Lac-St-Jean des Syndicats Nationaux.

Raymond Gérin, L.S.Soc., secrétaire du Comité paritaire de l'imprimerie et des arts graphiques de Québec.

Donat Quimper, LL.L., L.S.Soc., professeur à la Commission d'apprentissage de l'Intitut de la Chaussure de la province de Québec et directeur adjoint du Service de conciliation et d'arbitrage du ministère provincial du Travail. 